Illinois State University

ISU ReD: Research and eData

Theses and Dissertations

9-16-2016

\title{
Out the Window: The Coalescence of Internal and External Space
}

Micah Allen Zavacky

Illinois State University, micah.zavacky313@gmail.com

Follow this and additional works at: https://ir.library.illinoisstate.edu/etd

Part of the Theory and Criticism Commons

\section{Recommended Citation}

Zavacky, Micah Allen, "Out the Window: The Coalescence of Internal and External Space" (2016). Theses and Dissertations. 785.

https://ir.library.illinoisstate.edu/etd/785

This Thesis is brought to you for free and open access by ISU ReD: Research and eData. It has been accepted for inclusion in Theses and Dissertations by an authorized administrator of ISU ReD: Research and eData. For more information, please contact ISUReD@ilstu.edu. 
OUT THE WINDOW: THE COALESCENCE OF INTERNAL AND EXTERNAL SPACE

Micah Allen Zavacky

27 Pages

Out the Window: The Coalescence of Internal and External Space is a supportive statement for an exhibition of prints, drawings, and paintings that begin with direct observation. Building on Yi-Fu Tuan's distinctions of space and place, I examine how these terms reflect my subjective interpretations of objective subject matters. Landscape, still life in domestic interiors, and garden subjects, as observed and interpreted in the prints, drawings, and paintings, not only reveal the shifting roles of space and place but also the ongoing processes of change occurring both externally in the observed environment and internally in my response to it.

KEYWORDS: Art, Art History, Art Theory and Criticism, Direct Observation, Drawing, Empiricism, En Plein Air, Figure-Ground, Garden, Intaglio, Landscape, Oil Painting, Place, Printmaking, Relief, Space 
OUT THE WINDOW: THE COALESCENCE OF INTERNAL AND EXTERNAL SPACE

MICAH ALLEN ZAVACKY

A Thesis Supportive Statement Submitted in Partial

Fulfillment of the Requirements for the Degree of

MASTER OF FINE ARTS

School of Art

ILLINOIS STATE UNIVERSITY 
Copyright 2017 Micah Allen Zavacky 
OUT THE WINDOW: THE COALESCENCE OF INTERNAL AND EXTERNAL SPACE

MICAH ALLEN ZAVACKY

COMMITTEE MEMBERS:

Sarah Smelser, Chair

James Mai

Morgan Price

James Crowley 


\section{ACKNOWLEDGMENTS}

First and foremost, the writer would like to thank his parents, Billie and Derrick Zavacky, grandmother Linda Zavacky, and partner, Anthony Birchfield, for their unconditional love, support, and encouragement which has aided in the success of this journey. Secondly, the writer wishes to thank his fabulous and brilliant thesis committee for their guidance, mentorship, and patience during the completion of this thesis: the Gaia of printmaking with a laugh reminiscent of Gelos, Sarah Smelser; instilled with the power of Poseidon's waves, Morgan Price; the sage with a mind that rivals Minerva herself, James Mai; and the Thaleia-like Tony Crowley.

Additional thanks are given to the printmaking department at Illinois State University, including Sarah Smelser, Morgan Price, Veda Rives and professor emeritus, Richard Finch, who admitted the author into the graduate program. The writer also thanks Kim Vito, Penny Park, and Betty Peterson, impactful former teachers who continue to support the writer's efforts. This thesis is the reflection of many hours of hard-work and is imbued with the contributions of many people, organizations, and institutions.

The writer would like to give a special acknowledgement to the author, J.K. Rowling, who provided light in the darkest of times and whose life work has been a significant source of encouragement and hope.

Lastly, the author wishes to dedicate this document to his late grandfather, Alexander Zavacky, who did not see the author graduate but departed this world with the knowledge of the near completion of this degree. Alexander taught the author how to write neatly in free-hand as a child, and drove him through many of the Ohio backroads he grew to love. Thank you.

M. A. Z. 


\section{CONTENTS}

$\begin{array}{lr} & \text { Page } \\ \text { ACKNOWLEDGMENTS } & \text { i } \\ \text { CONTENTS } & \text { ii } \\ \text { FIGURES } & \text { iii } \\ \text { CHAPTER I: INTRODUCTION } & 1 \\ \text { CHAPTER II: ROOTED IN EN PLEIN AIR } & 3 \\ \text { CHAPTER III: PAUSING IN PLACE } & 8 \\ \text { CHAPTER IV: THE WINDOW AS STAGE AND EYE } & 16 \\ \text { CHAPTER V: ESTABLISHING PLACE IN THE SPACE OF MY GARDEN } & 22 \\ \text { BIBLIOGRAPHY } & 26 \\ \text { APPENDIX A: IMAGES ON DISC } & 27\end{array}$




\section{FIGURES}

Figure $\quad$ Page

$\begin{array}{ll}\text { 1. Underwood Park, Spring } 2016 & 7\end{array}$

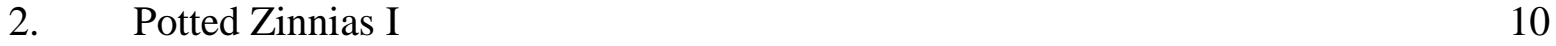

3. Potted Zinnias IV 11

4. Rachel Ruysch, Flowers in a Glass Vase 14

$\begin{array}{lll}\text { 5. Split } & 15\end{array}$

6. Out the Window: Succulent at Night II 17

7. Late Winter Evening 21 


\section{CHAPTER I: INTRODUCTION}

My hometown of Dayton, Ohio is a bizarre place that is filled with contradictions: trees appear to litter the urban landscape, the rich and poor live five minutes away from each other, and abandoned buildings are the leftovers of a more prosperous past. Growing up in Dayton, I was aware of the shortcomings of my surroundings and sought escape. My escape routes included the magical and fictional worlds of Harry Potter or X-Men, where anything can happen if you believe in the power of love and possess will, courage, and hope. As a child, fantasy became an escape from daily life, and has been replaced by my observation of landscape, still life, and garden in my work.

Ohio backroads, winding through wooded forests and rolling hills outside the Dayton city limits, provided another avenue of escape. As an adolescent, I longed to occupy both the imaginative realm of literature and the experiential latitude offered by the woods and countryside. My understanding of these experiences of youth has become clearer to me through my reading of Yi-Fu Tuan, who makes the distinction between space and place:

'Space' is more abstract than 'place.' What begins as undifferentiated space becomes place as we get to know it better and endow it with value... The ideas 'space' and 'place' require each other for definition. From the security and stability of place we are aware of the openness, freedom, and threat of space, and vice versa. Furthermore, if we think of space as that which allows movement, then place is pause; each pause in movement makes it possible for location to be transformed into place. ${ }^{1}$

This distinction between space and place continues to be important to the subject matter and content of my current studio work.

\footnotetext{
${ }^{1}$ Yi Fu Tuan, Space and Place (Minneapolis, University of Minnesota Press, 1977), 6.
} 
In my current artistic practice, I work from direct observation, focusing on the landscape, still life in domestic interiors, and the garden. By engaging with distinct parts of the natural world I have become better attuned to the importance of space and place in my work. My definitions of space and place are informed by Tuan, but are further shaped by my experience as an artist. I characterize place as locations that are familiar, comfortable, and meaningful; they are environments to which I feel connected and in which I experience heightened awareness. Space is, as Tuan says, more abstract: less familiar, more mysterious, less comfortable, unpredictable, and elusive. I am in space and there is a constant potential in all spaces to become places. Space and place are not static identifiers of geographical locations, but instead are malleable reflections of my relationship to a location; space becomes place when a personal connection is established.

By working observationally with the same spaces and subject matters, I develop attachment; the spaces become more familiar and ultimately evolve into places. While place and space are distinct, they are not mutually exclusive. It is not possible to have place present without space. In fact, space is needed to contrast the normality of place, and place is needed to provide stability in contrast to the openness of space. Both are at play wherever I make work, and both exist together in the images I create. It is my intention to articulate the similarities and differences between the landscape, still life, and the garden, and why all three are pertinent to my practice in their capacities as places and spaces. I will address the importance of space and place in relationship to working from direct observation. Lastly, I will explain how observed space becomes place through a dual sense of impression: both internally, as newfound experience, and externally as a process of making a print on paper. 


\section{CHAPTER II: ROOTED IN EN PLEIN AIR}

I adapt to the landscape. My approach to landscape is greatly connected to the process of en plein air, the tradition of drawing and painting from observation in the outdoors (also referred to as alfresco). Limitations of time, shifting light conditions, changes in weather, and changes in color temperature and value are typical challenges in this way of working. Painter Lois Dodd has been painting in the landscape for half a century, and she states a benefit of working outdoors:

What I really love about painting outside, no matter how you want to put it off, you can't... you gotta do it right then, right away. The sun is gonna move, the day is gonna change, the rain is gonna come... Whatever pressure it is, it makes you make up your mind and move. You don't have all month or all year to think about where the next brushstroke will go. If I am in the landscape, there's no way I'm going to come back a second time. I am not even the same person, it's not the same day... ${ }^{2}$

After only six years of working in the open air, I have learned to work quickly, instinctually, and without hesitation. I appreciate the challenge of resolving a drawing or painting in one session because my speed of work is influenced by pressures from nature. The landscape presents external stimuli and imposes limitations on the making of the work and my processes of creating an image. Like painter Fairfield Porter, I do not enter the landscape with absolute image-making strategies. Painter and critic Rackstraw Downes, recalls:

[Porter] ... painted what was immediately around him because it was the "easiest thing to do." He was interested, above all, in the process of painting. For him, painting was neither an emotional nor an intellectual activity; it was a process that made "the connection between yourself and everything... you connect yourself to everything which includes yourself." 3

${ }^{2}$ Robert Shatterly and Richard Kane, Lois Dodd: Maine Master (Brooksville, ME, Maine Masters Project of the Union of Maine Visual Artists, 2007).

${ }^{3}$ Klaus Ottmann, Fairfield Porter: Raw-The Creative Process of an American Master (Southhampton, NY, GILES in association with Parrish Art Museum, 2010), 15. 
When I am outside, I am most immersed in the process of drawing or painting because I am removed from the comfort of my home or studio. The landscape is more space-like, and I feel invigorated by the unknown of working en plein air. I value the inability to predict what pressures will impact my working session, the risk of success or failure of my image, and the knowledge that my return to a location, to continue working, will be different due to the outdoors' capricious nature. The ever-changing environment outdoors prevents my work from becoming static and repetitive. Outside there is a simple acceptance of limitations, and I become more aware of process, chance, and spontaneity. Like Porter, I just step outside somewhere with one simple objective - to make an image. The work completed alfresco is my most courageous; fear, incompleteness, and failure are put aside, and my task keeps me "in the moment." My focus stays with the immediacy of process in response to perceptual experience - this manifesting as an image, pure and free.

En plein air closely aligns the energy of the landscape to the energy I exert in my work. There is an interconnectedness between body, mind, and nature which is evident in the quick gestural marks, the absence of sharp edges, and the physical presence of material. In Nature and Culture, Barbara Novak, Professor Emerita of Columbia University, defines American landscapist identity by contrasting Hudson River painter Asher Brown Durand and French painter Gustave Courbet, “... the exigencies of outdoor circumstances foster painterly spontaneity of stroke and sensational responses to light and air that shift the surface away from the smooth, flat closure of the conceptual mode [Courbet] toward the 'breathing openness' of a more optical or perceptual mode [Durand]. ${ }^{.4}$ I recognize these qualities in my own working

${ }^{4}$ Barbara Novak, Nature and Culture: American Landscape and Painting 1825 - 1875, (New York, NY, Oxford University Press, 1995), 238. 
processes. Novak argues that spontaneity, gestural and expressive marks, and immense space in landscape painting are made possible by the external forces of nature, and this perceptual expression is derived from an American "... need to draw on the experience of nature [prior to] Cezanne." While the landscape is dynamically changing, I am also responding dynamically to those changes. Personal changes and that of my subject matter replenish my endeavors outdoors, resulting in innumerable outcomes. Novak suggests a difference between 19th century American and French en plein air methodologies: American pictures are guided by what artists saw (for example, rocks and trees), and French pictures are guided by how artists see (for example, the sensations of color and light). ${ }^{6}$ When I work alfresco, I let the observational process deepen my connection with space in an effort to make the landscape more place-like.

In my painting, Fig. 1. Underwood Park, Spring 2016 some brushstrokes are spatial indicators, while other brushstrokes contradict an illusion of pictorial space and emphasize the plane. The hasty application of paint reveals the gesso underneath, which shows how the changes occurring in my surroundings impact how I paint. The complex interrelationships among elements in the landscape are echoed in the variety of hues, resulting in an interplay of subject and color. Underwood Park, Spring 2016 possesses the qualities described by Novak because of my effort to keep up with the flux outdoors. In order to adapt to the landscape, I must increase my physical and mental pace, which results in an image that possesses a sense of urgency analogous to how I feel while painting en plein air.

Another important quality of Underwood Park, Spring 2016, is the balance between

${ }^{5}$ Barbara Novak, Nature and Culture: American Landscape and Painting 1825 - 1875 , (New York, NY, Oxford University Press, 1995), 241.

${ }^{6}$ Barbara Novak, Nature and Culture: American Landscape and Painting 1825 - 1875, (New York, NY, Oxford University Press, 1995), 239-241. 
specificity and ambiguity, a result of competing figure-ground relationships. Figure and ground denote active and passive attention to elements in our perceptual field. In a typical landscape, a tree or a mountain would be a figure against a plain or sky, which by contrast would be ground. The space in my painting is flattened and brought closer to the viewer due to the flux between figure and ground. This is an attempt to equalize figure and ground and to eliminate a hierarchy of subject matter; all shapes in the composition are important to formulate the whole. A redviolet egg shape sits in the negative space of the tree like a figure would sit in a tree. At the left border of the painting, a large vertical grey shape represents a tree and acts as a spatial device that overlaps one brown tree; this creates flatness and indicates the grey tree is closest. The language of this painting is representational and abstract, logical and whimsical, empirical and expressive. I began my painting of Underwood Park, Spring 2016 as an inquisitive explorer in an unfamiliar landscape, and at the end of the painting session, the park became a more familiar place. Plein air painting is an exploration carried out by experience as the eye and hand caress, follow, acknowledge, and translate the three-dimensional landscape onto a two-dimensional surface. It is through this process that the landscape becomes less space-like and more place-like. Over time, en plein air has become a process I utilize in an attempt to capture, accept, and work in tandem to change. The landscape possesses a plethora of visual information which ranges from kinetic movement to seasonal shifts. A painting/drawing session outdoors is a unique, self-contained, and autonomous response to a location; it is one encounter between my inner thoughts and a place. Multiple landscape images of different sites, perspectives, and times are unified by a consistency of interpretation of form, composition, and color throughout a series of paintings. As I become more aware of the changes in the landscape, I realize how I have changed and how that is manifested in the work. While I experience a freedom from self- 
consciousness, over-thinking, and control in the landscape, I am always aware of how rapidly time passes. In the spring, when I begin working outside, my pace is steady and my attention shifts from the relative constancy of indoor work to adapting to the less familiar space of nature. But as the summer progresses into autumn, I feel the urgency to work faster and more intensively in anticipation that my time outdoors is waning. Ultimately, long dark nights and the cold arrive, and I retreat indoors to pursue my studio endeavors with different subject matters in the comfort of place.

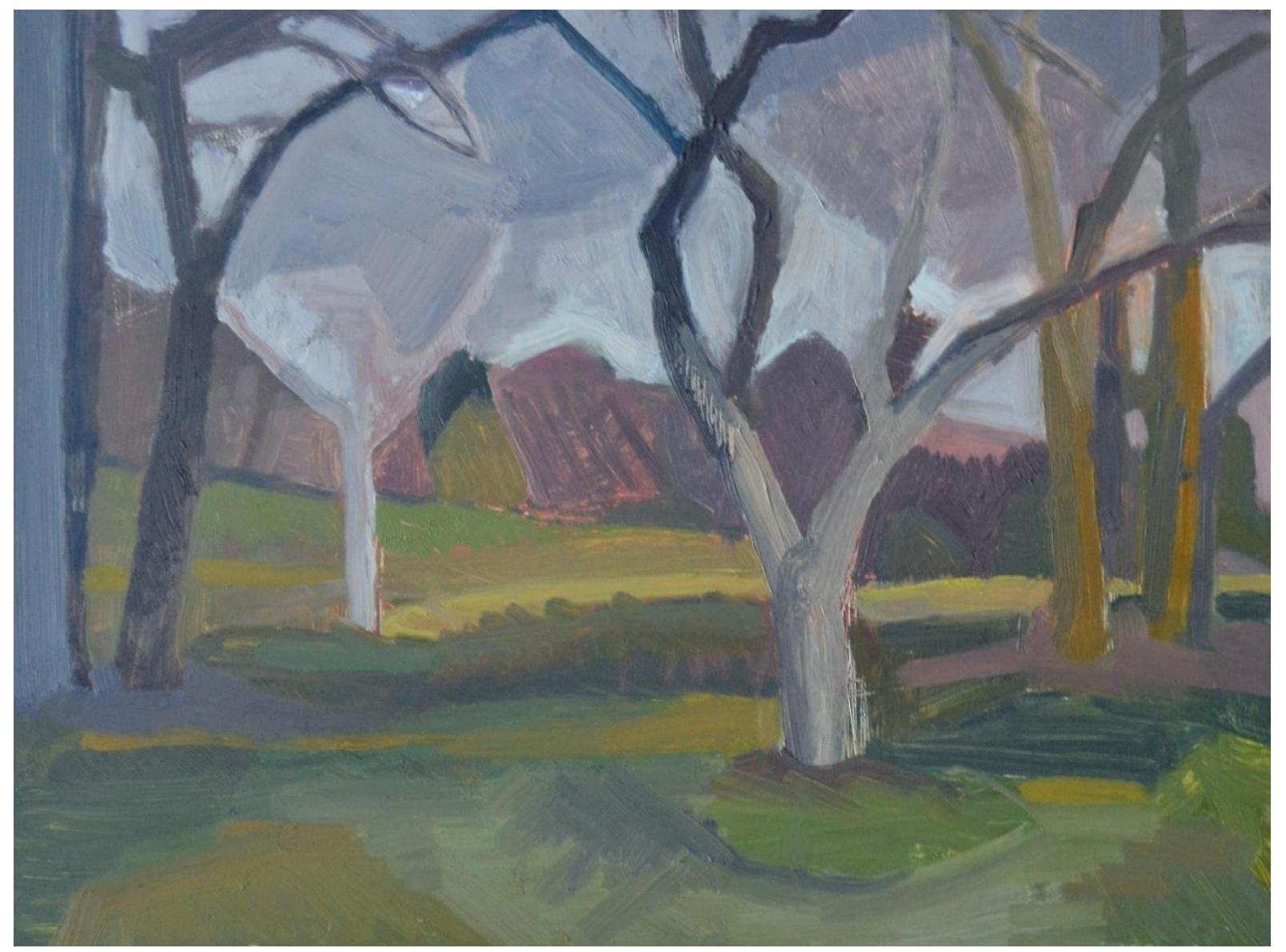

Fig. 1. Underwood Park, Spring 2016. Oil on panel, 9" x 12”, 2016 


\section{CHAPTER III: PAUSING IN PLACE}

It is a bit ironic that, despite my desire to work en plein air, I dedicate a large portion of my studio practice to the observation of indoor plants. A plant is a small representation of the natural world that I am able to bring into the studio to observe closely. In this environment, I can actively transform the composition by rotating, shifting, and modifying the still life. Whereas I orient myself to the landscape, I can orient the still life in response to my needs and intentions. With Tuan's ideas in mind, I have come to understand my work outdoors as occurring in spaces, and by contrast I regard the still life in my domestic setting as a place. Conceptually, the landscape and the still life exist on opposite ends of a spectrum: landscape is still natural despite human occupation, whereas household plants are domesticated and controlled.

Inanimate still life objects like cups and plates never change without my involvement, but living plants slowly grow or wither by themselves, often surprising me after long periods of time. The benefit of using indoor plants as still life subject matter is the extension of time. Compared to landscape painting, where light, color, and sometimes objects (clouds, for example) are rapidly changing, a still life seems static and even lifeless. Yet, the plant and the still life do change, just at a slower rate. Lighting is not the same from one working session to another, and the plant moves and grows in small increments. While I am able to adapt the still life to my needs, as an observer I am still adjusting to subtle and slow changes within the domestic sphere. This further reinforces the dynamic relationship I have with the subject. I feel myself "in process" in both landscape and still life settings. In contrast to en plein air, the still life makes me attuned to changes easily overlooked in the landscape.

I adapt to the changes that occur in the landscape, but when working from the still life, I exert change on the shapes and colors of the subject and adapt them to my purposes through 
abstraction. I abstract the still life more drastically than the landscape because abstraction allows me to transform the familiar into forms less known, thus the place-like still life becomes more space-like. Abstraction also gives me the liberty to invest the still life with psychological and emotional qualities.

One way I attempt to achieve a balance between naturalistic and abstracted images is through printmaking processes. I use printmaking to transform marks, to rework the plate, and to create different states. A state print is an impression pulled from a matrix (a metal plate or woodblock, for example) at a certain stage of development and is often followed by subsequent state prints, and/or an edition. Traditionally, state prints are pulled to show the printmaker what the current image looks like, but I create many state prints that stand alone as unique images. Rather than building towards a conclusion, all of my state prints are valid, resolved, and distinct works created in response to one another, without a final outcome in mind.

Working with the state process allows me to show change over several pieces, as in Fig. 2. Potted Zinnias I and Fig. 3. Potted Zinnias IV. In Potted Zinnias I, line is used to build the structure of the plant and create preliminary indications of form. This state shows that I am establishing composition, form, and value while keeping the image open for future development. Slowly, flowers and stems push towards the surface and are discernable, yet they are never solely flowers and stems, but also compositional shapes and values. Other ambiguities are present, such as a horizontal line that loosely divides the picture plane into two realms: above the flower heads are most prominent, and below the stems are emphasized. The openness at the bottom of the image contrasts with the heaviness of the top, and the dense cluster of lines combines with the 


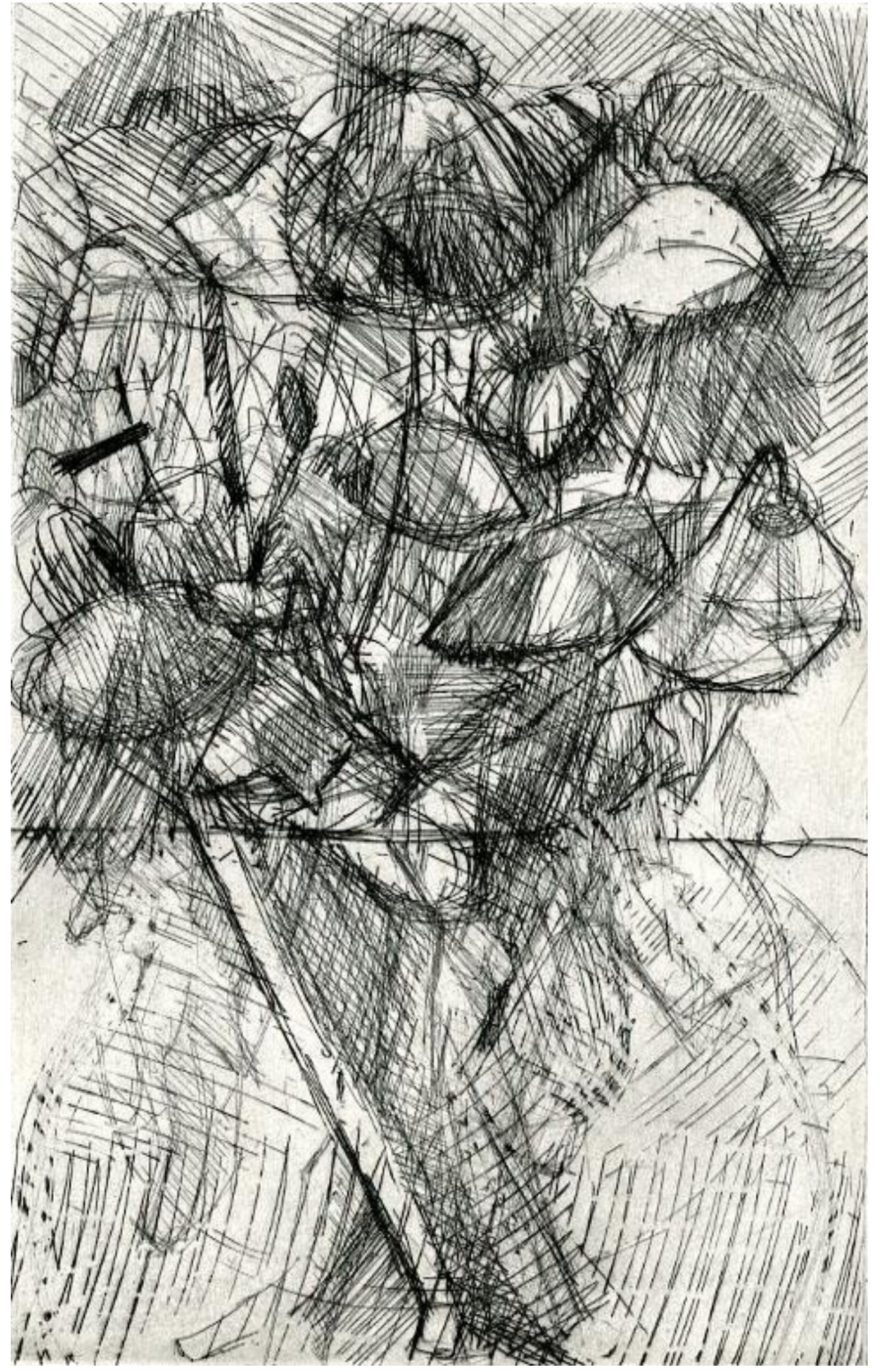

Fig. 2. Potted Zinnias I. Etching, 7” x 11”, 2016 


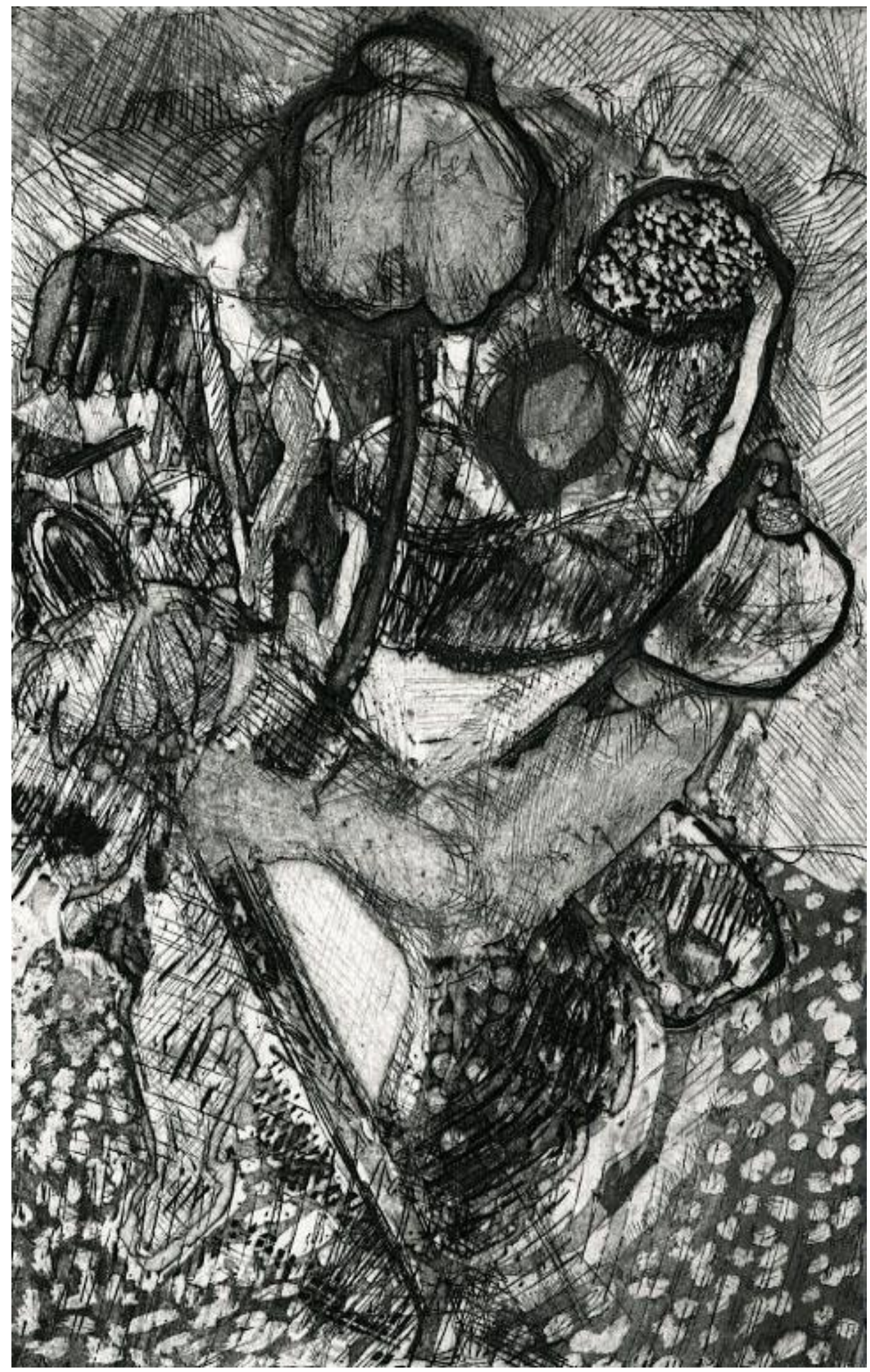

Fig. 3. Potted Zinnias IV. Etching, 7” x 11”, 2016 
abstracted flowers and leaves, fusing the plant with the background. I move from one print state to the next when I want to substantially modify and reorganize interactions among shape, value, pattern, and form.

A first state is a touchstone to which I can return when subsequent states become uncomfortable or confusing. I am able to create additional state prints with more confidence and sensitivity when I can see their history. In subsequent prints, I explore opportunities that started in previous states. Fig. 2. and Fig. 3. show a shift of emphasis from contour and structural lines to an abstraction of form and exploration of pattern. Potted Zinnias I is more directly shaped by the experience of observing the plant than subsequent states, which tend to use the resultant composition as the starting point. Potted Zinnias I is more representative of the plant, while Potted Zinnias IV emphasizes my engagement in printmaking processes. State impressions are physical manifestations of the evolution of the subject matter over time. Working in states allows me to preserve multiple renditions of one subject without eliminating one image for the benefit of the next. These prints do not show a linear progression; rather, they are an assortment of multiple, distinct moments of being.

Still life allows me to develop the work slowly and steadily, with an accumulation of complexity reminiscent of the Dutch Baroque still life painting, Fig. 4. Flowers in a Glass Vase, by Rachel Ruysch. She was the daughter of a professor of anatomy and botany and created still lifes characterized by varied and rich color and intricate attention to small shifts in light, volume, and texture. ${ }^{7}$ In her painting, the florae appear to be emerging out of the darkness, yet it is unclear if the florae are arising from their environment. Whereas Ruysch's painting possesses specificity

${ }^{7}$ Penelope J.E. Davies, Janson's History of Art: The Western Tradition (London, England, Pearson, 2010), 730. 
through subtle shifts in color and light, my etching Fig. 5. Split subdues figuration in favor of larger movements of shape, value, form, texture, and line. Despite the greater abstraction, my work shows an emergence of flowers from a background akin to Ruysch's painting. The flower heads in Split are articulated as white swirls with dark centers, locating the form of the flower while emphasizing a simple circular stroke as a rhythmical element. In both works, the flowers are emphasized through value contrasts of lighter figures against darker grounds.

After completing Split and reflecting on it, I recognize its connection to self-portraiture. The composition of Split shares some visual characteristics with most portraits and self-portraits. It is generally aligned along a central vertical axis. The flower cluster and negative spaces are located above the center of the picture plane, coming together to form a mass similar in structure to a portrait. In Split the flower cluster is the focal point, as is the head in a portrait. These compositional similarities allow me to recognize the internal self-portrait embedded in Split, a realization similar to my experience with en plein air work when I saw that changes in the landscape led me to a heightened self-awareness.

Viewing these plant etchings as both still life and self-portraiture allows me to express both domestic and psychological interiors. My treatment of the still life fulfills a desire to develop alternative modes of reordering what I see and feel, in an effort to make place more unknown and surprising. Working from still lifes with plants and flowers is an important contrast to working en plein air because it permits me time for abstracting and for contemplating related content (portraiture) to complement the specific subject matter (flowers). In analogizing selfportraiture and still life, I can regard the way I abstract the still life as an expression of my psychological and emotional space. 


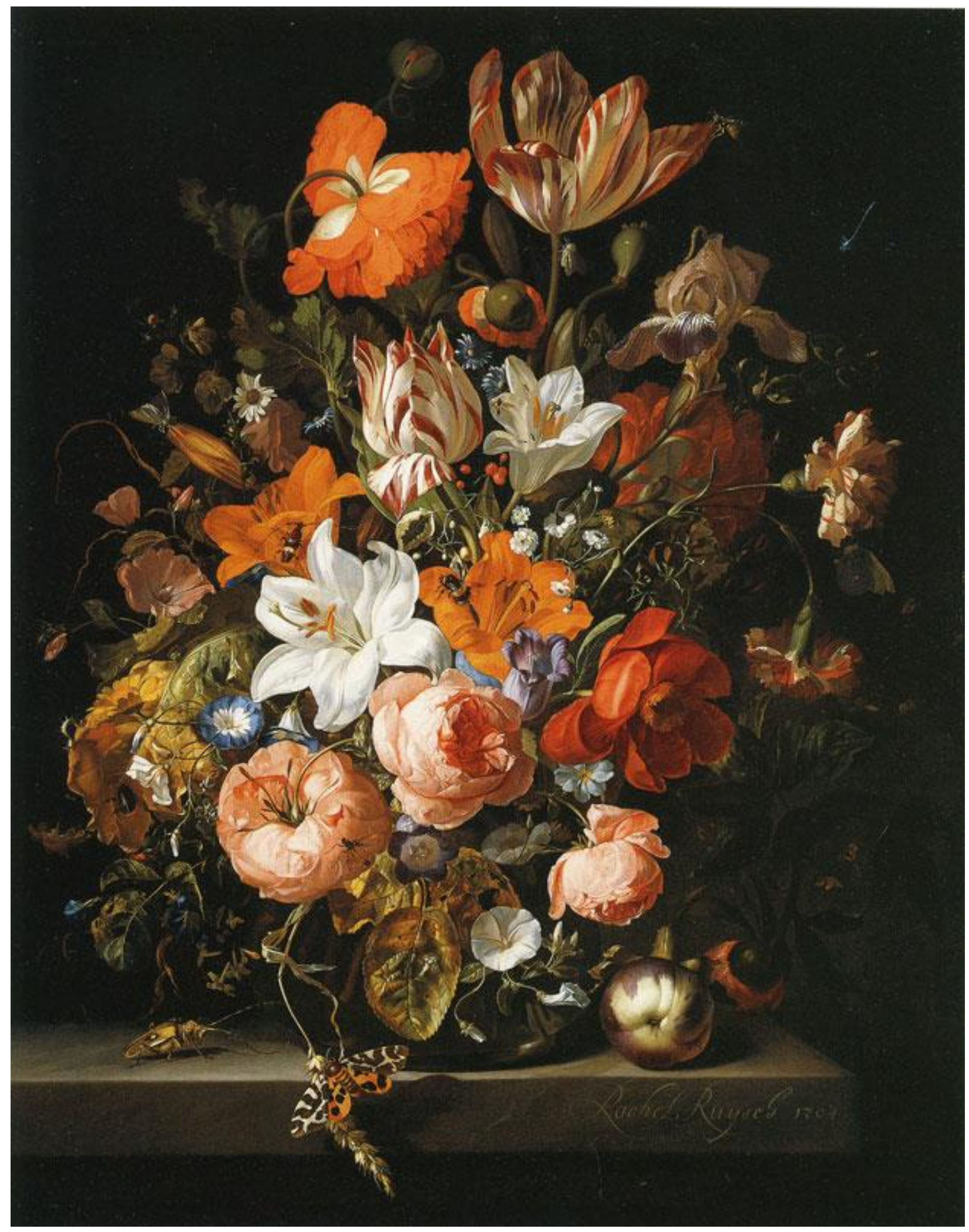

Fig. 4. Rachel Ruysch, Flowers in a Glass Vase. Oil on canvas, 33” x 26"3/, 1704 


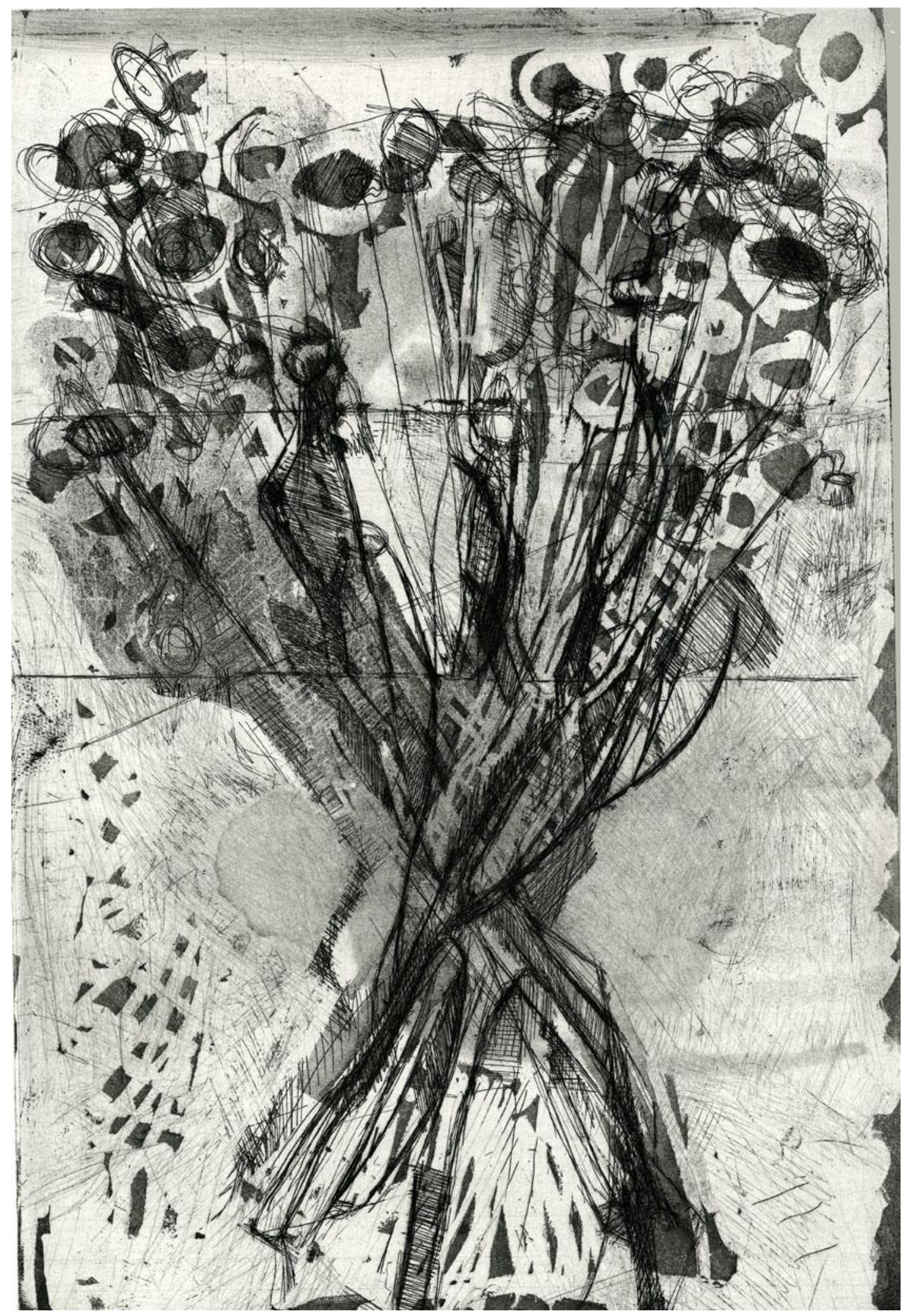

Fig. 5. Split. Etching, 12” x 18”, 2016 


\section{CHAPTER IV: THE WINDOW AS STAGE AND EYE}

Around November each year, I transition my studio work from the outdoors to the indoors, and a shift in emphasis occurs from landscape to still life. Windows appear in many of my still life compositions because they allow me to gain access to the landscape and outdoor light while remaining inside. At the same time, the window becomes a way to connect these subject matters because I can juxtapose interior still lifes, figures, and self-portraits with exterior landscapes. The window is an interesting middle-ground between interior and exterior and has become a space where I investigate fragmentation, containment, and immobility.

British painter David Hockney created a large body of paintings and drawings en plein air from his home landscape in Yorkshire. Hockney asserts, "Western perspective is about looking into a hole, or a window... a window on the world means you're cut off from the world... you want more than that really, you want to be in it." ${ }^{8}$ The window suggests a conflict between desire (to be outside and free to roam) and reality (being confined to an interior). Desire and frustration arise in the work as I accept my place indoors. This is expressed in my use of the window as a platform or lens to the outdoors.

I often use the window as a setting for a still life object, like a plant. In my drawing Fig. 6. Out the Window: Succulent at Night II the plant overtakes any visible space in the landscape outside the window. Instead, the plant is surrounded by the window sill as leaves, stems, and roots push towards and contact the top of the picture plane. The plant form is intensely lit by interior lights and is, in contrast to the ambiguity of the window pane, clear and in sharp focus. The window sill is where the plant receives the spotlight as the central actor in the

\footnotetext{
${ }^{8}$ Bruno Wollheim, David Hockney: A Bigger Picture (New York, NY, First Run Features, 2009).
} 
drawing. This drawing is like a self-portrait in more subtle and elusive ways than the etchings. In part, this is due to the less cohesive mass that can evoke a portrait-like head. The drawing has traditional mechanics of observation and illusion, as evidenced by the details of the plant. The drawing, despite its complex collection of shapes, is quickly resolved as a representation of a potted plant. Additionally, planar shifts and luminosity in the plant contrast with the dark window, which is flat and less active. In Out the Window: Succulents at Night II, the plant sits on the "stage" of a window sill as my reflection's stand-in. While I do not depict my reflection, I am aware of its vacillating presence as it dissolves and rematerializes.

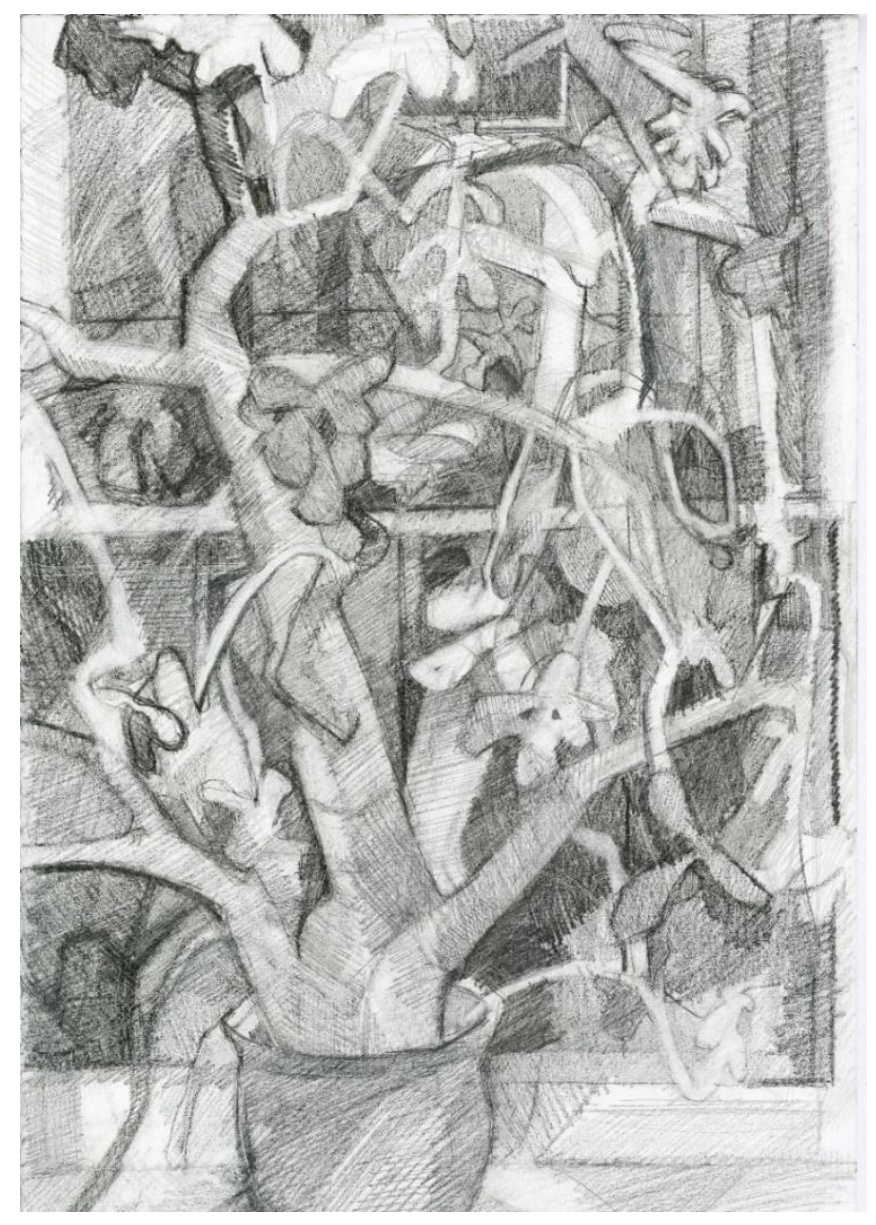

Fig. 6. Out the Window: Succulent at Night II. Graphite, 12" x 18”, 2016 
While the window can only offer fragments of the world outside, it has tremendous flexibility as subject matter; it allows me to consider division at many levels of meaning. In the woodcut Fig. 7. Late Winter Evening the window is the eye through which the garden outside can be viewed. Rather than depicting a specific interior space, I refer to the geometry and shape of the window economically. The identity of the window, expressed through moderate-sized black shapes, flattens the picture plane and gives a sense that the window frame is a part of the outdoors. By reducing the clear distinction between inside and outside, I disrupt the viewer's ability to easily interpret where he/she is situated within the pictorial space. Perceptual ambiguities are further encouraged by the treatment of the middle-ground and background, which become more active than the foreground and provide a sense of increasing light as the space recedes. My aim in carving the background with many lines and hatchings is to activate and bring into focus the subject that is most distant and unreachable. Perceptually, these visual characteristics create a subtle figure-ground ambiguity in the image, allowing the window to be apparent yet subdued, and the garden scene to be distant but clear.

The black border at the left, right, and bottom of Late Winter Evening is recognizable as a window frame, and it acts as the flattest area in the print. It has both a three-dimensional illusion and a two-dimensional compositional function. The flatness of the window frame allows the light in the garden and spaces across the street to come forward visually. This process is analogous to the way we see: the center of our visual field is bright and clear, but the periphery is darker and less distinct. Specifically, the shapes and marks in this woodcut are in constant motion where the perceivable world comes into focus, disappears, and reemerges like a reflection in a window. I hope that the awareness of both the window frame and garden scene correlate to a triadic awareness during observation: of oneself experientially and perceptually, of the mind and body, 
and of the observed subject. The alternating attention between the window frame and garden is the same experience I encounter when I am working from observation. In many ways, I attempt to reach a point during the creative process where I am engaged in a dialogue between my internal experience and the external stimuli, and this conversation becomes the work of art. This occurs as the chatter of self-consciousness and enforced expectations recede and awareness slowly builds.

My artwork is the arena where my subjective experience and thoughts meet with the objective world. In a pictorial space, I attempt to balance what I want in an image, receive from the subject matter, and express in materials. At times, this reconciliation can feel like a battle between opposites making resolution seem impossible. However, multiple sessions of direct observation reveal patterns, and the conflict produces an image I cannot predict. In Late Winter Evening, the lines and shapes create as well as undermine balance, refer to form while concealing volume, and create illusion while enforcing flatness. This creates perceptual activity throughout the image and makes the negative spaces that surround a tree as important as the tree itself. I am interested in using the contrasts in my work to disrupt the viewers' position within pictorial space. I want the viewers' perceptual experience to change as they question, hypothesize, ponder, and analyze how objective and subjective worlds merge into one another. Ultimately, I aim for the perceptual experience to parallel how a viewer comes to understand my work - a slow emergence of the flux between representational subject matter and compositional shapes, forms, colors, and spaces.

Over time, I have developed an appreciation for the window as a psychological as well as a physical screen between myself and the space outdoors. Whereas the landscape pressures me to create art more quickly and responsively, the window confronts me with the psychological and 
emotional oscillations rooted in day-to-day living. The window is unmoving, and in that inaction I am directed towards an image-making process of introspection which contrasts with the reactionary experience I have outside. Like the fluidity between space and place, the landscape and window encourage particular experiences while remaining malleable and unfixed. Typically, the landscape enlivens action and creation, and the window stimulates contemplation and rest in its passivity. While outdoors, I trace the landscape in a process that internalizes it and makes it more familiar to me. By contrast, through abstraction and shifting figure-ground relationships, I make still lifes in domestic interiors less familiar. In Late Winter Evening, the rhythm between illusion and flatness represents internal change as much as the window scene I am depicting. As an extension of still life and connection to landscape, the window is an empty mirror or picture plane in which I project personal-internal impulses on my subject matter. Ultimately, Late Winter Evening gives form to the indiscernible and unperceivable, making the apparently comfortable place resonate with the unknowable I associate with space. 


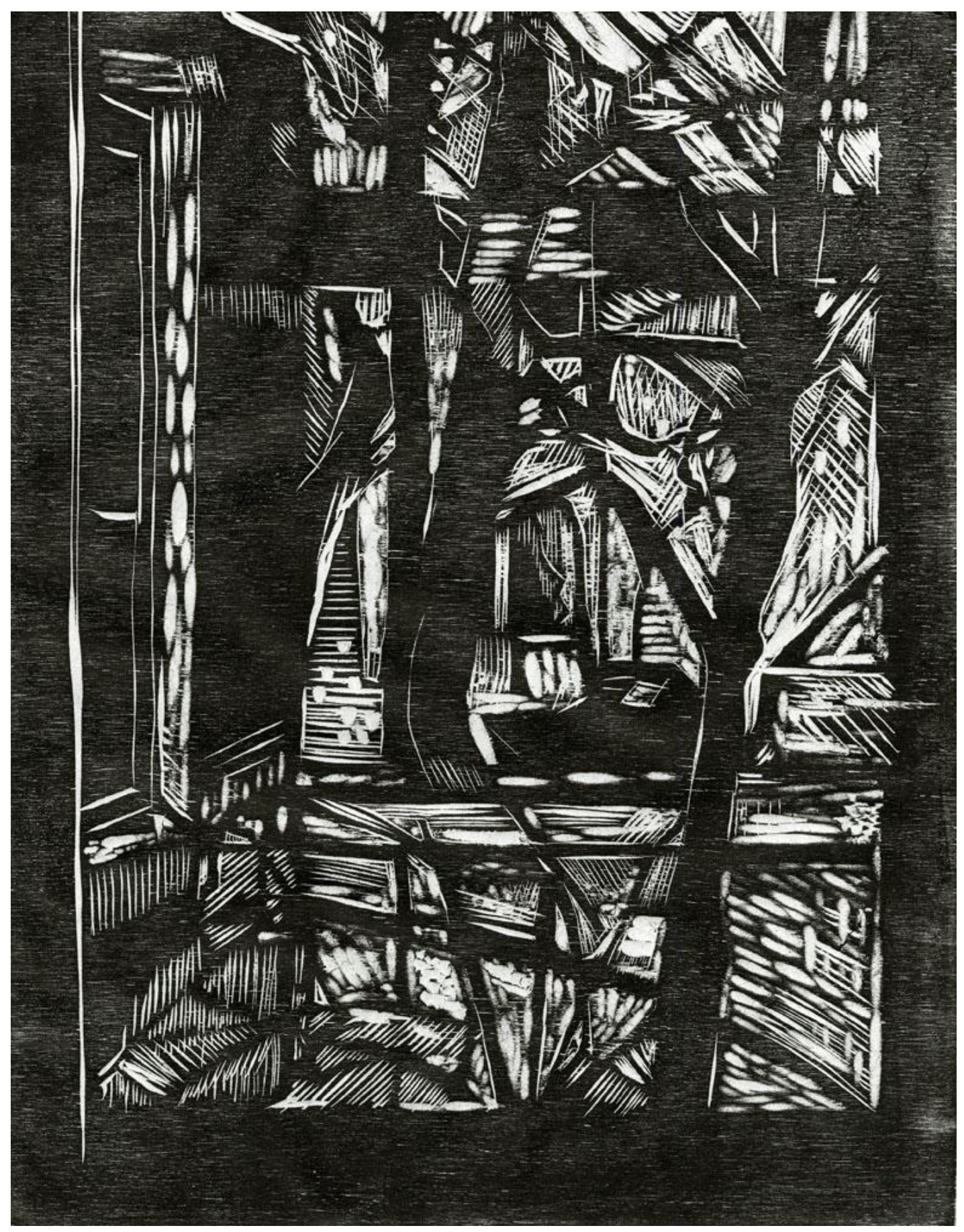

Fig. 7. Late Winter Evening. Woodcut, 12” x 18”, 2016 


\section{CHAPTER V: ESTABLISHING PLACE IN THE SPACE OF MY GARDEN}

The garden is a natural bridge between landscape and still life because it combines the uncontrollable qualities of natural space with the influence of human intervention. In some measure, plants can be controlled or manipulated within a garden, but factors such as sunlight, temperature, and seasonal changes affect the garden as much as they do the natural environment. Observing a garden is engaging because I can interact with it daily and be surprised by its unpredictability. Aside from its role in personal-private spheres, a garden has had many functions across time, cultures, and geography: as part of a temple for spiritual or religious enlightenment, as an expression of power, as a control over nature, and as a place to heal and prepare for death. ${ }^{9}$ For me, the garden is one way to gain “... a sense of control over a small patch of earth in spite of all that is left to chance..."10 Over time, I have come to believe that all artists, in some capacity, create work out of a need to reorder the world. I consider my studio work as a kind of garden, and myself as a gardener tending to its growth. Among the many reasons I create, I aim to reorder the observable and perceivable world into a place in which I feel at home and where I can be an active participant.

In the garden I can address the nature of Tuan's space and place, and engage in solitary activities like wandering, gazing, meditating, thinking, and imagining - personal introspection transforms the garden into a contemplative environment. Concurrently, the garden can be a place (in Tuan's sense) where people commune, and in the garden I am always aware of the close proximity between private and public spaces. I would not say I chose the garden as a subject

${ }^{9}$ Mark Francis and Randolph T. Hester, Jr., The Meaning of Gardens: Idea, Place, and Action (Cambrdige, MA, The MIT Press, 1990), 10-17.

${ }^{10}$ Mark Francis and Randolph T. Hester, Jr., The Meaning of Gardens: Idea, Place, and Action (Cambrdige, MA, The MIT Press, 1990), 6. 
because I was aware of the parallels between my studio work and the act of gardening. Rather, questions and contrasts arose in my plant and landscape images, which led me to think of the garden's special quality as a middle-ground that possesses aspects of each. Ultimately, my work in the garden is a deliberate attempt to make a zone where space and place are equalized —close to the domestic interior where I work with still life, yet possessing the unpredictable and uncontrollable processes of the natural world.

In the garden as in society, there is an ongoing battle of seeming oppositions: male versus female, good versus evil, reaction versus revolution, self versus community ... bigness versus smallness, sacred versus profane, science versus intuition, high versus folk art. Some of these conflicts in the garden are age-old, while others are a result of modern life (and a desire to control and order our personal worlds). ${ }^{11}$

I resist, question, and accept change while making art. I crave control while recognizing how much I cannot control. I embrace change yet I fear it. I long to be safe and loved in a place, yet also to be completely detached and free in a space. In The Meaning of Gardens, it is stated, “... apparent irreconcilables are clarified and mediated because the garden accepts paradox". ${ }^{12}$ The garden accepts paradox because it is the negotiation or middle-ground between many contrasts, and I see the same things in my artwork. Unified images are composed of areas where contrasting forces collide, battle, and reconcile. Most importantly, opposing forces give meaning and value to each other through their similarities and differences. I am interested in the ways in which my work expresses my thoughts and observations, much as a garden might suggest the

\footnotetext{
${ }^{11}$ Mark Francis and Randolph T. Hester, Jr., The Meaning of Gardens: Idea, Place, and Action (Cambrdige, MA, The MIT Press, 1990), 4.

${ }^{12}$ Mark Francis and Randolph T. Hester, Jr., The Meaning of Gardens: Idea, Place, and Action (Cambrdige, MA, The MIT Press, 1990), 6.
} 
gardener's intentions, and provide opportunities for interpretation and participation from an audience.

Gardens are mirrors of ourselves, reflections of sensual and personal experience. By making gardens, using or admiring them, and dreaming of them, we create our own idealized order of nature and culture... Since the beginning of human time, we have expressed ourselves through the gardens we have made. They live on as records of our private beliefs and public values, good and bad. ${ }^{13}$

Ultimately, I aim to create work through direct observation that is an honest synthesis of what I observe, of what happens in my daily life, and how I experience and reflect upon these occurrences. The garden is where the line between space and place overlap and perhaps even unify. I hope to understand myself and my relationship to the perceived world, forging meaning from change and difference and coming to terms with the flux of space and place.

The garden has become a place of personal enjoyment and artistic expression to me. As a temporary tenant of my landlord's garden, I have adopted it as my own despite my not having planted it. Conceptually, I tend to this garden by creating art. My prints, drawings, and paintings are reflective of how I reorder space to create a visual world for myself-a place, in Tuan's terminology. The landscape, still life, and garden are three facets of the natural world that have become the focus of my studio work because the changes those subjects undergo deeply impact me. The notion that, "gardens are mirrors of ourselves" resonates with me, and in analogizing the garden to my studio work, I realize the changes and occurrence in landscape, still life, and garden make me more attuned to my own growth and transformation, and as an active, adaptive, responsive interpreter of my world.

\footnotetext{
${ }^{13}$ Mark Francis and Randolph T. Hester, Jr., The Meaning of Gardens: Idea, Place, and Action (Cambrdige, MA, The MIT Press, 1990), 2.
} 
In the garden, I have discovered a middle-ground between domestic interiors and landscapes that unifies the various subjects and processes I use to generate works of art. My quest to articulate the motivation and underlying content of my artwork offers new realizations. The natural world has clarified my direction and reinforced my commitment to representing both what I see before me and what I discover within. I am confident that my work in the future will be guided by the knowledge that internal content is made visible through the study of objective subject matter. I first thought my work was a singular response to what I saw, but now I know that place and space reside in me and are given form in the works I create through landscape, still life, and garden. The world of natural forms and internal discoveries intertwine in infinite variations and provide a rich foundation for a lifetime of work. 


\section{BIBLIOGRAPHY}

David Hockney: A Bigger Picture. Wollheim, B. (Director). (2009, June 15, 2010).[Video/DVD] New York, NY: First Run Features.

Davies, P. J. E., Denny, W. B., Hofrichter, F. F., Jacobs, J. F., Roberts, A. S., and Simon, D. L. (2010). Janson's History of Art: The Western Tradition (8th ed.). London, England: Pearson.

Francis, M., and Hester, R. T., Jr. (Eds.). (1990). The Meaning of Gardens: Idea, Place, and Action. Cambridge, MA: The MIT Press.

Gayford, M. (2011). A Bigger Message: Conversations with David Hockney. New York, NY: Thames \& Hudson.

Maine Masters Project of the Union of Maine Visual Artists (Producer), Shatterly, R. and Kane, R. (Directors). (2007). Lois Dodd: Maine Master. [Video/DVD] Brooksville, ME.

Novak, B. (1995). Nature and Culture: American Landscape and Painting 1825-1875 (Revised Edition with a new preface ed.). New York, NY: Oxford University Press.

Ottmann, K. (2010). Fairfield Porter: Raw-The Creative Process of an American Master. Southhampton, NY: GILES in association with Parrish Art Museum.

Tuan, Y. (1977). Space and Place: The perspective of experience. Minneapolis, MN: University of Minnesota Press. 


\section{APPENDIX A: IMAGES ON DISC}

$1 \quad$ Underwood Park, Spring 2016

$2 \quad$ Potted Zinnias I

$3 \quad$ Potted Zinnias IV

4 Rachel Ruysch, Flowers in a Glass Vase

$5 \quad$ Split

6 Out the Window: Succulent at Night II

$7 \quad$ Late Winter Evening

8 Installation Shot (1/3)

$9 \quad$ Installation Shot (2/3)

10 Installation Shot (3/3) 